\title{
Using an ocean model to predict likely drift tracks of sea turtle carcasses in the north central Gulf of Mexico
}

\author{
Redwood W. Nero ${ }^{1, *}$, Melissa Cook ${ }^{2}$, Andrew T. Coleman ${ }^{3}$, Moby Solangi $^{3}$, \\ Robert Hardy ${ }^{4}$
}

${ }^{1}$ NOAA Fisheries, Southeast Fisheries Science Center, Bldg 1021, Stennis Space Center, Mississippi 39520, USA

${ }^{2}$ NOAA Fisheries, Southeast Fisheries Science Center, 3209 Frederic St., Pascagoula, Mississippi 39567, USA

${ }^{3}$ Institute for Marine Mammal Studies, 10801 Dolphin Lane, Gulfport, Mississippi 39503, USA

${ }^{4}$ Florida Fish and Wildlife Conservation Commission, Fish and Wildlife Research Institute, 100 Eighth Avenue SE, St. Petersburg, Florida 32399, USA

\begin{abstract}
From March through July 2011, an increased number of Kemp's ridley sea turtles Lepidochelys kempii were reported stranded on the islands, beaches and shorelines of Louisiana, Mississippi and Alabama. Members of the National Sea Turtle Stranding and Salvage Network responded, documenting the location and physical condition of each turtle. This report describes an ocean physical model-based analysis of the spring and summer 2011 Mississippi stranding events. Included within this group of strandings was 1 satellite-tagged moribund Kemp's ridley turtle, initially alive and tagged by the Institute for Marine Mammal Studies for a site fidelity study. Data from this tracking event provided an accurate time sequence of $58 \mathrm{~h}$, during which the animal was presumed to be drifting, based on observed characteristics that were typical of a floating carcass. Turtle drift data were combined with output from the America SEAS (AMSEAS) hydrodynamic model to provide an estimate of leeway. The AMSEAS model was then applied to an additional 247 stranded turtles to produce $5 \mathrm{~d}$ Lagrangian backtrack drifts to derive mortality source location probability maps. Based on the model presented in this study, the majority of mortalities appeared to have occurred in eastern Louisiana state waters.
\end{abstract}

KEY WORDS: Kemp's ridley · Sea turtle $\cdot$ Lepidochelys kempii · Stranding · Lagrangian Backtracking

\section{INTRODUCTION}

The Kemp's ridley sea turtle Lepidochelys kempii, currently classified as Critically Endangered by the IUCN (MTSG 1996), is listed as endangered under the US Endangered Species Act of 1973, and was once feared to be near extinction if immediate conservation and management measures were not taken (Carr 1977). Due to the bi-national efforts of the US and Mexican governments, the number of annual nests has increased at an annual rate of about $15 \%$ from 1990 to 2009 (Heppell et al. 2007, Crowder \& Heppell 2011, NMFS et al. 2011). An arribada of approximately 9000 females was documented during the 2011 nesting season (NOAA 2011). Increases in the number of annual nests are likely due to protection of nesting beaches, eggs and females by the Mexican government, mandatory regulations requiring turtle excluder devices (TEDs) by the US and Mexican shrimp fisheries (Magnuson et al. 1990, Frazier et al. 2007), and decreased shrimp fishing effort (Heppell et al. 2007, NMFS et al. 2011, DEIS 2012). The population increases are expected to result in an increased occurrence of Kemp's ridleys in the northern Gulf of Mexico (GOM) (Shaver \& Rubio 2008). Satellite-tagged Kemp's ridley sea turtles have been 
observed occupying nearshore waters from Texas to the Florida Keys, with a 'hotspot' located from south Texas to the Florida panhandle (Shaver \& Rubio 2008). This area contains abundant crab and shrimp populations and appears to be a primary foraging area for juvenile Kemp's ridley sea turtles (Shaver \& Rubio 2008, Seney \& Landry 2011, Lyn et al. 2012).

Starting in 2010, sea turtle strandings increased throughout the entire GOM (Sea Turtle Stranding and Salvage Network [STSSN] unpubl. data) (www.sefsc. noaa.gov/species/turtles/strandings.htm); however, the north central GOM saw the largest increase (cold stun events excluded) relative to prior decades. On average, from 1986 through 2009, 97 sea turtle strandings occurred per year in Louisiana, Mississippi and Alabama combined (STSSN unpubl. data). Then, in 2010, sea turtle strandings in this region significantly increased to a total of 644 (DEIS 2012, STSSN unpubl. data). Federal and State Natural Resource Trustees are investigating the turtle injuries and deaths associated with the Deepwater Horizon (DWH) oil spill which occurred in 2010. In 2011, high numbers continued at 525, especially during the March to July 2011 period, with 455 strandings (STSSN unpubl. data). The stranded turtles were primarily juvenile Kemp's ridley $(85 \%)$ and lesser numbers of loggerhead and green sea turtles (Table 1). The high numbers of strandings observed in the north central GOM during 2010 and 2011 were noted as an unusual series of strandings by the NOAA Fisheries Service.
Table 1. Number of stranded sea turtles by species in Louisiana, Mississippi, and Alabama, USA, in March through July 2011 (Data from Sea Turtle Stranding and Salvage Network, STSSN). The Mississippi count of Kemp's ridley turtles by STSSN differs from that run in the analysis in the present study (248) because of a recalculation of stranding dates

\begin{tabular}{|lccc|}
\hline Species & Louisiana & Mississippi & Alabama \\
\hline $\begin{array}{l}\text { Loggerhead } \\
\text { Caretta caretta }\end{array}$ & 13 & 4 & 7 \\
$\begin{array}{l}\text { Green } \\
\quad \text { Chelonia mydas }\end{array}$ & 4 & 4 & 1 \\
$\begin{array}{l}\text { Kemp's ridley } \\
\text { Lepidochelys kempii }\end{array}$ & 83 & 251 & 57 \\
$\begin{array}{l}\text { Unidentified } \\
\text { Total }\end{array}$ & 12 & 6 & 13 \\
\hline
\end{tabular}

The greatest concentrations of stranded sea turtles were documented on beaches of the Mississippi Gulf Coast (STSSN unpubl. data; Fig. 1), with 194 reported in the state of Mississippi. Only 13 strandings occurred in Louisiana State waters east of the Mississippi River delta. The active depositional lobe of the Mississippi River delta (referred to as the 'bird's foot') is generally considered a barrier to east-west transport within the estuary. Seven of the 13 were Kemp's ridleys that were found stranded in marshes on the west side of Chandeleur Sound, but dates and precise locations were not available from the State of Louisiana. Only 58 strandings were found in Alabama;

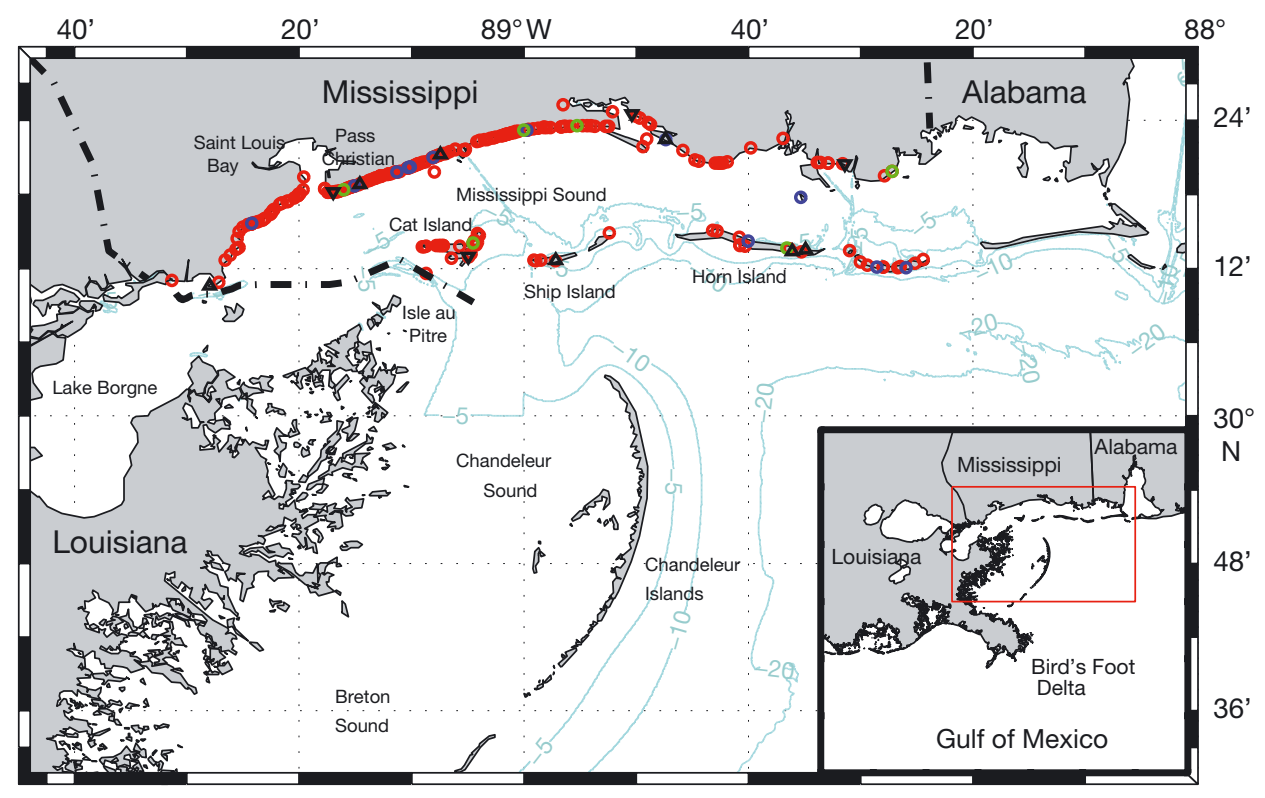

Fig. 1. Distribution of sea turtle strandings in Mississippi during 2011 ( $\mathrm{n}=277$ ). Of these, 260 were Kemp's ridley turtles Lepidochelys kempii, 247 during March to July (O) and 13 during other months (O), 6 were green turtles Chelonia mydas (O), 4 were loggerhead turtles Caretta caretta $(\nabla)$, and 7 were unidentified $(\Delta)$. Bathymetry $(5 \mathrm{~m})$ is shown in light blue 
most were recovered from ocean-facing beaches and in Mobile Bay. Throughout the March to July 2011 stranding events, National Marine Fisheries Service (NMFS) and Institute for Marine Mammal Studies (IMMS) personnel worked cooperatively, documenting the location, morphometrics and physical condition of each turtle. Most of the carcasses (83\%) were found in a moderate to severely decomposed state, but still sufficiently intact to float onto beaches. Based on water temperatures, the carcasses were estimated at 2 to $5 \mathrm{~d}$ post-mortem (Higgins et al. 2007). Concern over the unusually high number of strandings on the Mississippi beaches led to a concerted effort by the NMFS, Mississippi Department of Marine Resources and IMMS to determine the source location for the initial mortality and prompted the present study. Estimation of the source location for the initial mortality would allow the NMFS to focus their efforts on specific areas to determine the cause of the mortalities and to seek remedies.

This report documents an ocean physical modelbased analysis of the March to July 2011 stranding events. Objects at sea drift in a complex way as a sum of the components of direct wind, wind-induced swells and waves (Stokes drift), and ocean currents (components reviewed by Breivik et al. 2011). For sea turtle carcasses, the appropriate parameters and contribution of each component are unknown. Studies of virtual larvae using Lagrangian simulation is a rapidly growing field, but such studies usually deal with drift

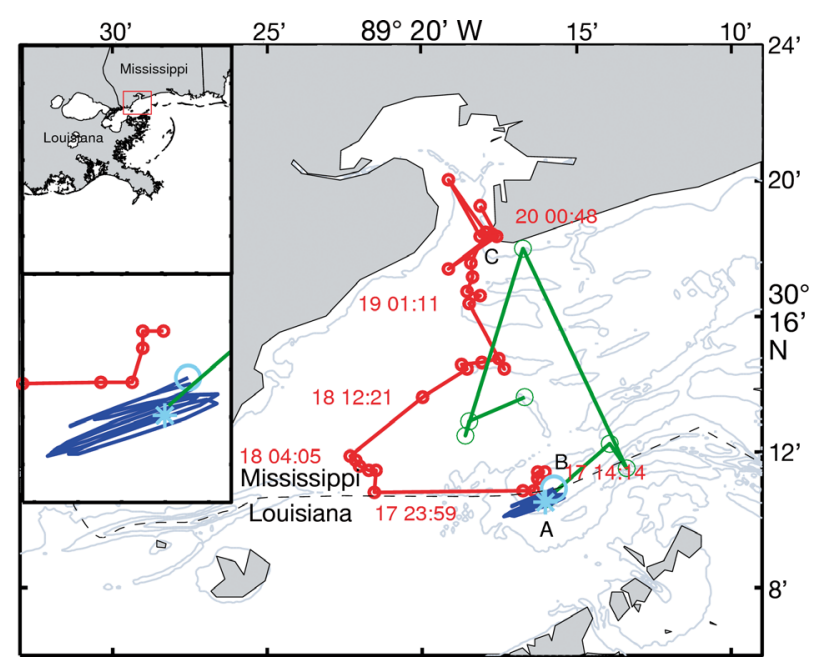

Fig. 2. Lepidochelys kempii. Final Argos satellite track of Kemp's ridley LK41, showing track 3 d before death (-), probable location of death (*), model-generated bottom drift $(-)$, with bottom drift end $(O)$ and drift fixes $(O)$. Times are given as day in March and GMT. Top inset: location of study region. Lower inset: detail of bottom drift (-). Bathymetry $(1 \mathrm{~m})$ is shown in light blue in the upper mixed layer rather than a floating object (reviewed by North et al. 2009, but see Breivik et al. 2012 for man-made objects). Although a limited number of forensic backtrack studies have used virtual trajectories to hypothesize the possible source of drifting carcasses (Peltier et al. 2012), or human remains (Carniel et al. 2002), none have been conducted on sea turtle carcasses except Hart et al. (2006), who looked at general seasonal flow patterns and overall results of drift bottle experiments to infer stranding likelihood. Our approach used a 2-step modeling exercise to determine the likely source of the mortalities. First, a satellite-tagged moribund turtle (alive when initially tagged) provided a unique opportunity to obtain an accurate time sequence of $58 \mathrm{~h}$ of drift characteristics, from 14:14 h GMT, 17 March to 00:48 h GMT, 20 March 2011 for what we assumed was a typical floating carcass. Second, the results of fitting leeway drift estimates from an ocean model now-cast to this satellite-tagged animal were then applied to backtrack for up to $5 \mathrm{~d}$ an additional 247 stranded Kemp's ridley sea turtles found in Mississippi State waters and beaches in 2011 to derive their likely source locations.

\section{MATERIALS AND METHODS}

\section{Satellite telemetry}

As part of ongoing tracking studies of sea turtles in the northern Gulf of Mexico by the IMMS, an Argos satellite platform terminal transponder was attached to the anterior dorsal carapace of a rehabilitated juvenile Kemp's ridley sea turtle, using Powers T308+ epoxy. The turtle, designated PTT102741 (hereafter LK41), was released on 23 November 2010 and was tracked for ca. $11 \mathrm{wk}$. During this time, transmissions indicated that LK41 inhabited Mississippi Sound waters, south of Pass Christian, Mississippi, with relatively normal movement behavior characterized by variable transmission quality typical of live and active marine animals, which spend little time at the surface and are often unable to send multiple messages during Argos overpasses (Vincent et al. 2002). After a final position at 17:53 h GMT on 12 March (Fig. 2, position A), the position of LK41 was not estimated by Argos again until 14:14 h GMT on 17 March (Fig. 2, position B). On 17 March, LK41 began transmitting from a location near where transmissions ceased on 12 March, approximately $14 \mathrm{~km}$ south of Pass Christian, Mississippi. The distance between the final location on 12 March and the first location of 17 March was $1.4 \mathrm{~km}$ (represented by the asterisk at A to the 
red circle at B in Fig. 2). On reappearing after this $116 \mathrm{~h}$ pause, LK41 exhibited a marked increase in Argos location class quality. The prevalence of Argos Location Class 3 positions, the highest possible location class quality (Vincent et al. 2002), indicated that LK41 was spending all of its time at the surface and transmitting several messages during each Argos overpass. Furthermore, location data collected after 17 March exhibited low travel speeds (median = $1.05 \mathrm{~km} \mathrm{~h}^{-1}$ ) with characteristics suggesting that the animal was floating at the surface until stranding on the beach at 00:48 h GMT on 20 March (Fig. 2, position $\mathrm{C}$ ). The general track depicted is accurate as locations of Class 3 have 95th percentile error estimates of $326 \mathrm{~m}$ latitude and $742 \mathrm{~m}$ longitude (Vincent et al. 2002). Based on the characteristics of the Argos positional data, we assumed that mortality occurred after 17:53 h GMT on 12 March. The animal may have remained submerged for $5 \mathrm{~d}$ and then resurfaced for the final $3 \mathrm{~d}$ of transmissions.

Studies of sea turtle decomposition suggest that carcasses will initially sink upon death and remain on the bottom until gas generated from decomposition results in their floating to the surface (B. Higgins et al. unpubl.). Water temperature plays a key role in the time for gases released by decomposition to result in floating, with rates estimated as $24 \mathrm{~h}$ at $30^{\circ} \mathrm{C}$ and 4 to $5 \mathrm{~d}$ at $20^{\circ} \mathrm{C}$ (B. Higgins et al. unpubl.). Water temperatures from the oceanographic model (described below), suggest bottom temperatures were $\sim 16.8^{\circ} \mathrm{C}$ initially and increased to $19.2^{\circ} \mathrm{C}$ at the submergence location for LK41. Applying the rates estimated by B. Higgins et al. (unpubl.), these temperatures would have resulted in a submerged period of about 4 to $5 \mathrm{~d}$, which matches the observed submergence of $116 \mathrm{~h}$ (4.8 d). Currents queried from the oceanographic model for the time and place of the last Argos fix and the submergence period show they were oscillating on a $24 \mathrm{~h}$ tidal cycle, in the east-west direction $(u)$ at -20 to 0 to $+20 \mathrm{~cm} \mathrm{~s}^{-1}$ and the north-south direction $(\mathrm{V})$ at -2 to 0 to $+5 \mathrm{~cm} \mathrm{~s}^{-1}$, resulting in a net displacement while submerged of about $1 \mathrm{~km}$ north (Fig. 2, blue track).

\section{Lagrangian tracking}

The north central Gulf of Mexico is characterized by diurnal tides of low amplitude, with a spring tide maximum of about $90 \mathrm{~cm}$ and a neap range of about $10 \mathrm{~cm}$ (Seim et al. 1987). Mississippi Sound is shallow, of $4 \mathrm{~m}$ average depth, and protected by a chain of barrier islands with wind waves both fetch- and depth-limited, with very little development of swell.
Just offshore in the Mississippi Bight, southeast of Ship Island, with a north wind, wave energy dissipates almost simultaneously with decreasing winds (Rogers et al. 2003). Due to the strong dependence of the wind waves on wind strength in Mississippi Sound, we make no attempt to model the wave conditions and instead consider all components of the wind forcing in the following leeway parameterization.

Surface currents and wind forcing used in estimating leeway and subsequent carcass drift backtracks were obtained from the American SEAS (AMSEAS) implementation of the Navy Coastal Ocean Model (NCOM). AMSEAS gives a $3 \mathrm{~h}, \sim 2.8 \mathrm{~km}$ resolution, $1000 \times 1510$ grid domain of the Gulf of Mexico and Caribbean Sea, and includes tidal, geostrophic, and atmospheric-driven water motion. Wind forcing (as wind stress) and other atmospheric parameters within AMSEAS are from the Navy regional Coupled Ocean/Atmosphere Mesoscale Prediction System (COAMPS ${ }^{\circledR} ;$ Hodur 1997, Chen et al. 2003). Further information on these models can be found through the Northern Gulf Institute (NGI) site (www.northerngulfinstitute.org/edac/) and descriptions of the Navy Operational Global Atmospheric Prediction System (NOGAPS).

Turtle carcasses were tracked as Lagrangian surface particles forced by velocity $U$ in the east $(u)$ and north $(v)$ direction using:

$$
\begin{gathered}
U_{u, v}=\tilde{C}_{u, v}+W_{u, v}^{\prime} K+P_{u, v} \alpha\left\|\tilde{C}_{u, v}+W_{u, v}^{\prime} K\right\| \\
W_{u, v}^{\prime}=\tilde{W}_{u, v}-\tilde{C}_{u, v}
\end{gathered}
$$

at 15 min time steps with a second-order Runge-Kutta method augmented with a 3-step iterative re-interpolation of the endpoint velocities. The first term of Eq. (1) gives particle motion as the sum of model-generated currents, $\tilde{C}$, and the apparent wind forcing, $W^{\prime}$, adjusted by a sea turtle leeway drift coefficient, $K$. In Eq. (2) apparent wind, $W^{\prime}$, is calculated as the difference between model-derived wind velocity, $\tilde{W}_{\text {, }}$ and current velocity, $\tilde{C}$. Using apparent wind gives more realistic results, such as when wind and current velocities are equal, the wind forcing is zero and all motion is from the current. Conversely, a strong current running against the wind results in a wind forcing greater than the current or wind alone. All interpolations from the approximate $3 \mathrm{~km}$ AMSEAS model output to exact positions were linear. Hydrodynamic models cannot capture turbulent motion below the grid scale of the model, so instead, an accepted method is to reincorporate sub-grid scale turbulent motions using a random flight model (Marinone et al. 2004, Carlson et al. 2010, Johnson et al. 2013). This 
simulation of turbulent motion is accomplished in the 2nd term of Eq. (1) with a Gaussian probability density function, $P_{u, v}$ (mean $\left.=0, \mathrm{SD}=1\right)$ multiplied by a fraction $\alpha$ of the overall particle motion magnitude, $\left\|\tilde{C}_{u, v}+W_{u, v}^{\prime} K\right\|$. The choice of $\alpha$ is somewhat ad-hoc; however, a value of $\alpha=0.1$ during a 1/10th day time step roughly approximates upper layer ocean turbulence and our $\alpha^{2}$ is equivalent to the eddy diffusivity (Carlson et al. 2010). As our Lagrangian drift model uses output from fixed $3 \mathrm{~h}$ time steps in the AMSEAS hydrodynamic model, we set $\alpha=0.1$ and applied the random walk at $3 \mathrm{~h}$ intervals (1/8th day) to be approximately similar to that selected by Johnson et al. (2013). Scaling the random walk to some measure of the time step is critical, as finer or coarser choices result in less or greater stochastic behavior, respectively. Choice of $\alpha$ does not influence mean trajectories, but only the overall spread. The AMSEAS output data does not directly include wind, but rather $u$ and $V$ vectors of wind stress. Wind stress was converted back to wind velocity, $W$, assuming a uniform air density of $1.3 \mathrm{~kg} \mathrm{~m}^{-3}$ and a coefficient of drag based on conversions given in Trenberth et al. (1990).

Bathymetry at a $189 \mathrm{~m}$ grid (1/600 degree) from the National Geophysical Data Center (NGDC) for the north central GOM region as well as vector shoreline data were used to provide boundary conditions for headlands and bays in the region of Mississippi Sound, such that tracks would more realistically impinge upon and disperse around these features. For modeling at the coast, values for current and wind velocity were extrapolated outwards by about $1 / 2$ to 1 pixel ( 1 to $3 \mathrm{~km}$ ) to ensure complete coverage where the AMSEAS grid does not match the above definitions for the shoreline (sensu Paris et al. 2005). In a few extreme cases, a 2 pixel extrapolation was used for small bays and estuaries.

Several choices of leeway, $K$, in Eq. (1), ranging from 0.02 to 0.05 ( 2 to $5 \%$ ), were evaluated against the observed $58 \mathrm{~h}$ Argos track of LK41. For a measure of the quality of fit, we used the average track error (TE) calculated as the mean distance between hourly interpolations of the Argos positions and corresponding (based on time) positions of 1000 particles in the Lagrangian model.

\section{Carcass backtracking}

Backtracking was performed by evaluating Eq. (1) with reversed sign on all vectors and by stepping through the time sequence of AMSEAS output in reverse order. Timing to begin backtracks was estimated in the following way for 248 strandings (including LK41), 189 occurring on popular beaches and 52 at remote sites, and 7 found drifting. Popular beaches were those adjacent to residential or tourist areas. Strandings on popular beaches were assumed to be observed by a member of the public at least once in a $24 \mathrm{~h}$ period. Hence, the mean time for the probability distribution of stranding detection on a calendar date would be the middle of the daytime period (06:00 to 18:00 $\mathrm{h}$ ), with the actual stranding event having occurred on average in the preceding $24 \mathrm{~h}$ period, and with the midpoint of stranding occurring at midnight local time. Backtracking was therefore initiated at 06:00 h GMT (midnight local). For those found drifting, the actual time was not noted so these were initiated on the day of stranding at noon local time $(18: 00 \mathrm{~h}$ GMT). For remote sites on barrier island beaches and marshes, the frequency of observation was estimated at about $4 \mathrm{~d}$ prior to detection, based on the assumption that most remote islands and beaches were visited by recreational fishermen, National Park Service staff, or workers contracted for oil spill cleanup at least twice a week. As the backtracking routine was depth sensitive, with movement stopping on land, many of the exact GPS-recorded positions at or above high tide were adjusted seawards by about $300 \mathrm{~m}$. These seaward adjustments were made perpendicular to the shoreline with the maximum adjustment being $\sim 1000 \mathrm{~m}$ for a shallow sloping barrier island.

The Lagrangian drift model with leeway for an ensemble of 1000 particles was applied to each seaward-adjusted carcass location to initiate drift backtracks for up to $5 \mathrm{~d}(120 \mathrm{~h})$. Backtrack times were based on a time-temperature dependent decomposition model. Carcass decomposition was previously studied for 2 freshly dead Kemp's ridley specimens at approximately 20 and $30^{\circ} \mathrm{C}$ by Higgins et al. (2007) in the surf zone off Texas. The specimen evaluated at $30^{\circ} \mathrm{C}$ experienced uncertain temperatures on collection and during the test. However, the $20^{\circ} \mathrm{C}$ specimen provided a reliable time-temperature history to which we fit, through the origin, a linear degree-hour decomposition rate with a base of $0^{\circ} \mathrm{C}$, the temperature at which decomposition is assumed to cease (Megyesi et al. 2005). The resulting relationship for carcass condition (Codes 1 to 5) gives 1 step-change for 1500 accumulated degree-hours (ADH). In applying this to each backtrack, the particle-averaged ADH was used to estimate the time spent drifting (TSD) based on the STSSN observer's reporting of carcass condition and the along-backtrack ADH required to reach back to Code 2 (moderately decomposed). TSDs were then used to estimate likely backtrack drift times. We used 
the observation of $1100 \mathrm{ADH}$ for LK41 from the time of first floating at the sea surface (presumed Code 2) to stranding at the beach to calibrate the decomposition model for a Code 3 (severely decomposed) carcass. Since the AMSEAS model assimilates all available thermal imagery, of which several images may be available per day, the along-track estimates of accumulated temperatures for LK41 are presumed reliable. Overall, most carcasses were Code $3(n=171)$. Codes 4 (dried carcass) and 5 (skeleton, bones only) were less frequent ( $\mathrm{n}=30$ and 6 , respectively). Several Code 1 carcasses (freshly dead) stranded $(n=4)$, also suggesting that even freshly dead specimens may float. Code 1 carcasses $(n=4)$ were arbitrarily assigned a $24 \mathrm{~h}$ drift time (1 tidal cycle), and Code 2 carcasses $(\mathrm{n}=36)$ an ADH of $550(1 / 2$ that of 1100$)$ or a minimum $24 \mathrm{~h}$ drift time, whichever occurred first. TSDs exceeding $120 \mathrm{~h}$ were truncated at $120 \mathrm{~h}(\mathrm{n}=33)$.

Backtrack results were confirmed by calculating forward drift trajectories from the estimates of where carcasses likely began drifting. This is somewhat like the technique described by Breivik et al. (2012) but restricted to the first iteration. Drift durations were those derived using the ADH model described above.

Multiple carcass backtracks were then combined by smoothing and fitting the density of all outcomes.

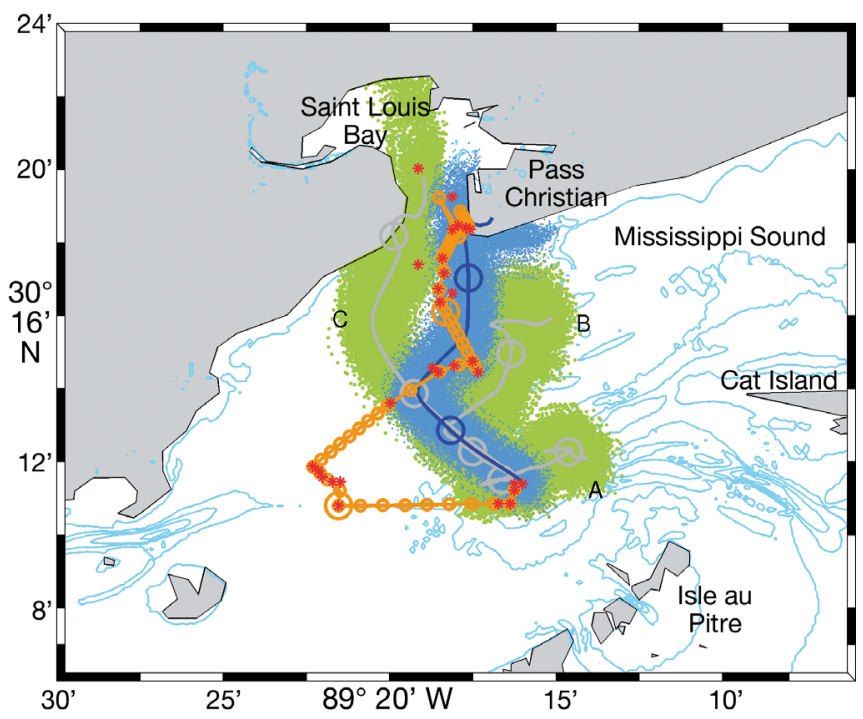

Fig. 3. Forward Lagrangian particle drift fit to a presumed dead and floating Kemp's ridley (LK41). Argos track (-) with satellite fixes (*) and hourly interpolations $(\bigcirc)$. Large circles depict $24 \mathrm{~h}$ intervals. (-) Best fit with a leeway speed of $3.5 \%$ of wind speed and cloud (blue) of 1000 particles demonstrating random diffusivity. The green clouds with mean tracks (-) demonstrate less successful leeway choices: (A) $0 \%$ leeway, giving net displacement from currents alone; (B) $2 \%$ leeway; and (C) $8 \%$ leeway. Bathymetry $(1 \mathrm{~m})$ is shown in light blue
To examine time trends in potential stranding sources, the 2011 strandings $(n=248)$ were examined within calendar date ranges as March $(n=49)$, April $(n=131)$, May through June $(n=53)$ and July $(n=15)$. For each date range, smoothed particle density was divided by the total average particle density to create a Probability Density Function (PDF) of turtle mortality. Only 3 strandings occurred in January and February and 10 in August to December; therefore these months were not used in the density maps. All analyses were restricted to strandings that occurred within approximately 60 nautical miles of the initial observed drift of LK41 (those close to Mississippi Sound waters), as our estimate of leeway drift may not be applicable to more energetic ocean conditions found far beyond the protected waters of the Mississippi and Chandeleur sounds.

\section{RESULTS}

\section{Leeway estimate}

The best overall track fit to LK41 obtained using wind-induced drift (leeway, $K$ ) calculated from wind stress in AMSEAS, was found using $K$ set at $3.5 \%$ of the wind speed (Fig. 3). The lowest TE values occurred for leeway values of 3.0 and $3.5 \%$ (alongtrack mean $\mathrm{TE}=1.4$ and $1.7 \mathrm{~km}$ respectively). Although the 3.0 and $3.5 \%$ values are close, the $3.5 \%$ curve (Fig. 4) was considered superior as it provided

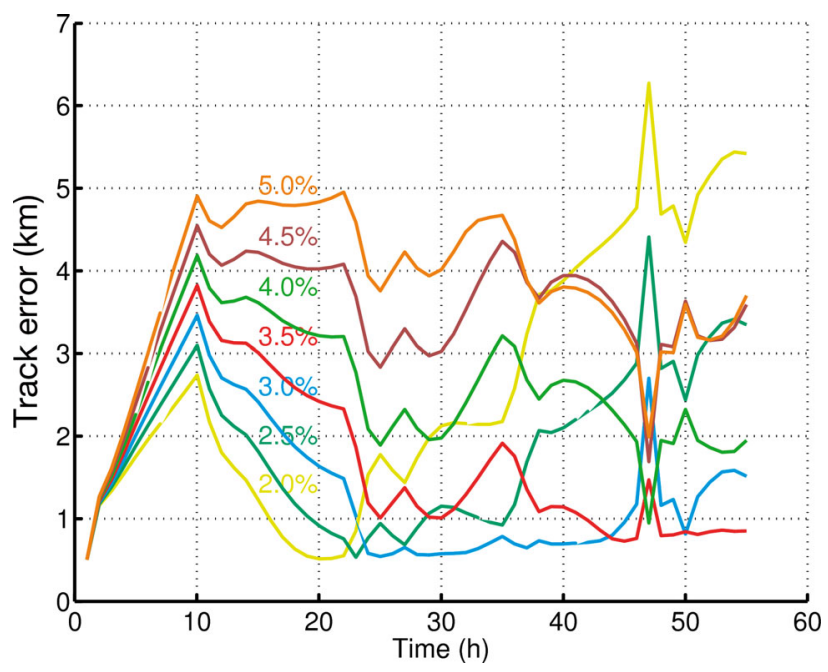

Fig. 4. Forward trajectory Lagrangian drift model at different values of leeway $(K)$ as percentages, fit to a presumed dead and floating Kemp's ridley (LK41) along track positions based on interpolation of Argos positions. Along track averages of track error in ascending order (averages of curves 2.0 to $5.0 \%$ ) were: $2.6,1.9,1.4,1.7,2.6,3.4$, and $3.8 \mathrm{~km}$ 
smaller TE estimates, especially for the final $12 \mathrm{~h}$ as LK41 approached landfall. Two other choices depicted in Fig. 3, with $K$ of 2 and $8 \%$, show either insufficient drift to the north $(K=2 \%)$ and no stranding, or excessive drift and a resultant stranding off Bay Saint Louis, Mississippi $(K=8 \%)$. A multitude of other leeway values in $0.5 \%$ increments over these 2 examples were evaluated but produced poorer fits than $K=4 \%$ (additional tracks not shown for clarity).

LK41's initial westward and then northeastward motion during the first $24 \mathrm{~h}$ of the drift sequence could not be completely matched regardless of choice of leeway. The best explanation is that the AMSEAS model underestimated the east-west motion of the currents in Mississippi Sound during this time. The particle drift with no leeway (Fig. 3, track A) shows the small westward then eastward displacement based on the ocean currents, but these were insufficient to produce the resulting east-west drift of LK41. For the next $24 \mathrm{~h}$, both modeled and actual drifts matched well, showing slow northwards motion ending off Pass Christian, Mississippi.

The ability of the AMSEAS with a leeway of 3.5\% to reproduce LK41's drift track is further exemplified in Fig. 5 with particle launches at $3 \mathrm{~h}$ intervals along

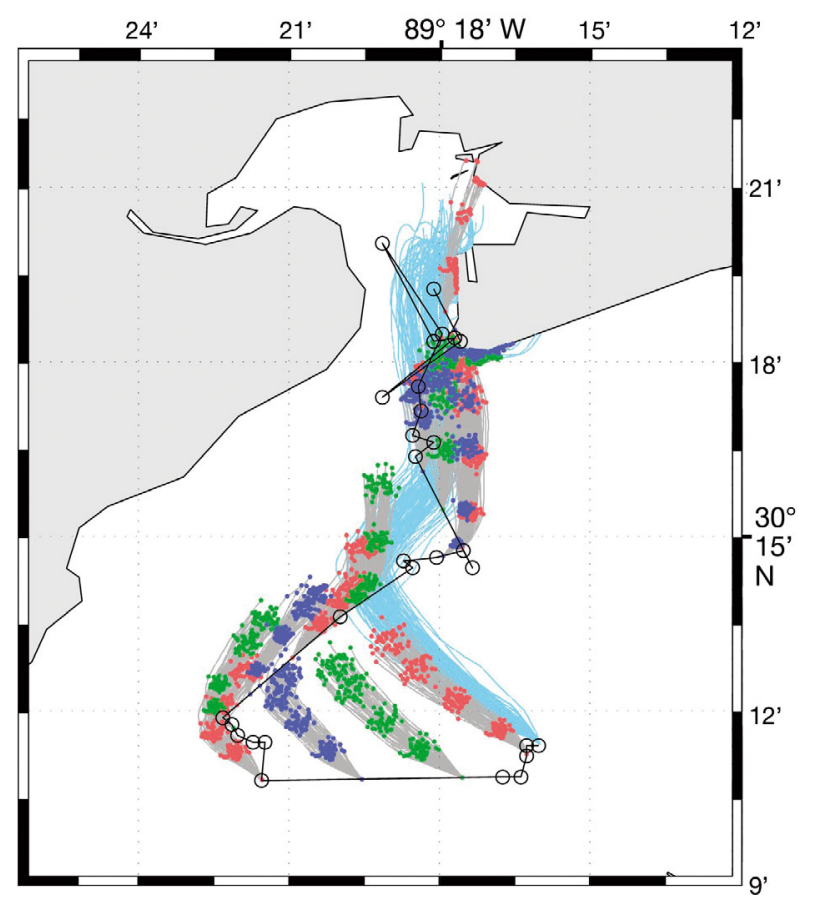

Fig. 5. Forward Lagrangian particle drifts of $12 \mathrm{~h}$ duration released at $3 \mathrm{~h}$ intervals along the interpolated Argos track of LK41 with alternating red, green, and blue clouds for illustrative purposes. Forward model used a leeway speed of $3.5 \%$ of wind speed. Underlying light blue track is 1000 particles demonstrating random diffusivity of multiple tracks for a single release point run over the entire $58 \mathrm{~h}$ drift the interpolated Argos track. Particle clouds at $3 \mathrm{~h}$ intervals also show the inability of the model to replicate the westward and then northeastward motion of LK41. The latter half of LK41's drift shows better model to data agreement.

Underrepresentation of east-west motion of the tidal currents in Mississippi Sound could not be evaluated for March 2011 because direct measurements of currents were unavailable. However, beginning in spring 2012 a higher resolution coastal model, the Northern Gulf of Mexico Operational Forecast System (NGOFS) was implemented by the NOAA. Comparison of the NGOFS and AMSEAS for 1 yr later, March 2012, at a location in mid-Mississippi Sound near where LK41 drifted $\left(30.21^{\circ} \mathrm{N}, 89.30^{\circ} \mathrm{W}\right)$, provides confirmation that AMSEAS tended to underrepresent tidal-based currents at this location (Fig. 6). However, the astronomical tides in Mississippi Sound are generally oscillatory, and amplitude errors in the northeast and southeast will tend to cancel in a $24 \mathrm{~h}$ tidal cycle (Fig. 6). Most drift estimates in this study extend beyond one $24 \mathrm{~h}$ tidal cycle, which was the case for the drift of LK41. Furthermore, with a leeway of $3.5 \%$, most of the net forcing is from the wind which is highly directional over periods of many days (Fig. 6).

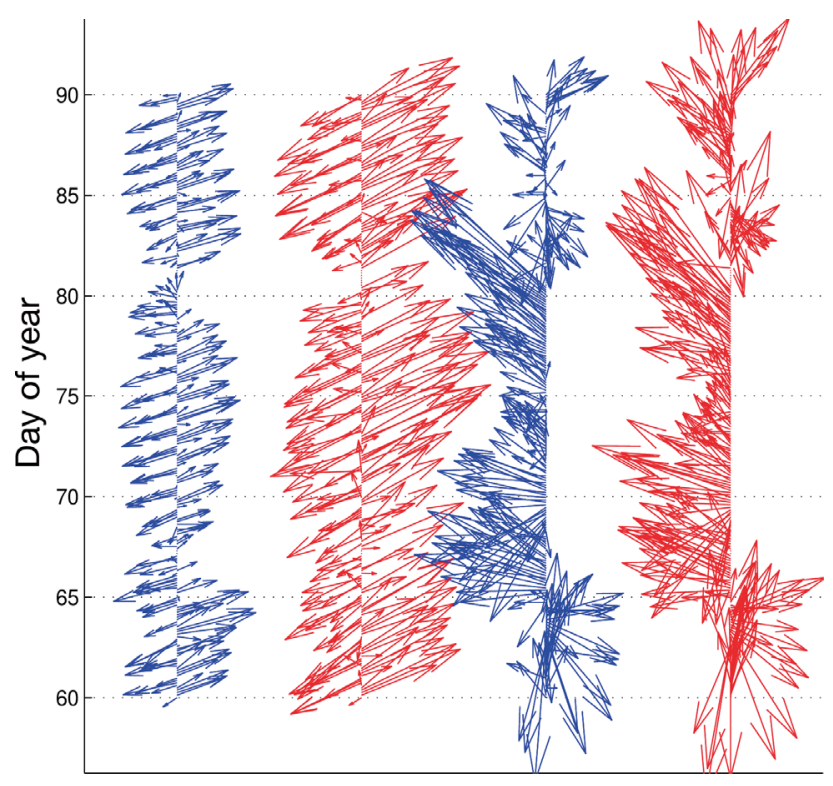

Fig. 6. Surface current vectors (left 2 columns) and wind vectors (right 2 columns) from the America SEAS (AMSEAS) hydrodynamic model (blue) and the Northern Gulf of Mexico Operational Forecast System (NGOFS) hydrodynamic model (red) plotted at $3 \mathrm{~h}$ intervals for the calendar month of March 2012 (Days 60 to 90 of year, vertical axis). Vector arrow scales are arbitrary, but scaled consistently within the current and wind columns with winds scaled $\times 0.04$ 
Winds from 2 nearby Coastal-Marine Automated Network (C-MAN) stations located on the west side of Saint Louis Bay (WYCM6, 30.326 ${ }^{\circ} \mathrm{N}, 89.326^{\circ} \mathrm{W}$ ) and Ship Island (GPOM6, 30.230 $\mathrm{N}, 88.982^{\circ} \mathrm{W}$ ) and the AMSEAS output from along the modeled drift track provide confirmation of the general wind patterns estimated during the drift of LK41 (Fig. 7). Both sources indicated that winds shifted from the southeast to south and decreased from $4-5 \mathrm{~m} \mathrm{~s}^{-1}$ to near calm at $24 \mathrm{~h}$. From 24 to $48 \mathrm{~h}$, coinciding with the passage of a cold front, winds then increased and veered from east through south to west and finally north. Wind speeds and directions changed rapidly near the end of the track (50 to $58 \mathrm{~h}$ ). Initially, the $2 \mathrm{C}$-MAN stations matched well; however, later in the drift sequence, winds further offshore at Ship Island tended to be higher than the more inland site (Saint Louis Bay). Early in the sequence, the AMSEAS estimated winds matched the buoys well, but later in the sequence, the AMSEAS gave lower wind speeds than both buoys. Some of this discrepancy can be attributed to the $3 \mathrm{~h}$ averaging window which smoothed high values and gave low values when winds were rapidly veering (48 to $51 \mathrm{~h}$ ). The $6 \mathrm{~km}$ resolution of the COAMPS system also contributed to the disagreement between estimated and observed winds.

\section{Backtracking}

Backtracking results are shown for LK41 in Fig. 8, the remaining backtrack results for all 248 carcasses in Fig. 9. For the known drift of LK41, the backtrack algorithm provided an extremely good estimate of its original site of mortality, where the backtrack estimate was within about $2 \mathrm{~km}$ of its presumed death (Fig. 8A). A convenient way to represent numerous backtrack outcomes is to plot vector arrows for both backtrack and ensuing forward trajectories shown in isolation for LK41 (Fig. 8B), and referred to as outbound tracks (dotted grey line) and inbound tracks (solid red line).

Fig. 8. (A) Sea turtle carcass backtrack model described in the text with time truncated according to the decomposition rate estimates for LK41. (@) Stranding site of LK41, (O) Argos position estimate of beginning of LK41 drift. The backtrack is shown in blue and the source location estimated from the model in orange. Bathymetry $(1 \mathrm{~m})$ is shown in light blue. (B) Example trajectory plot for LK41 as vector lines connecting average particle endpoint positions, $(-\rightarrow)$ Outbound backtrack trajectory with cloud (blue) of estimated source location, and $(\longrightarrow$ ) inbound forward trajectory. $(\bigcirc)$ stranding site; $(\bigcirc)$ forward trajectory stranding site

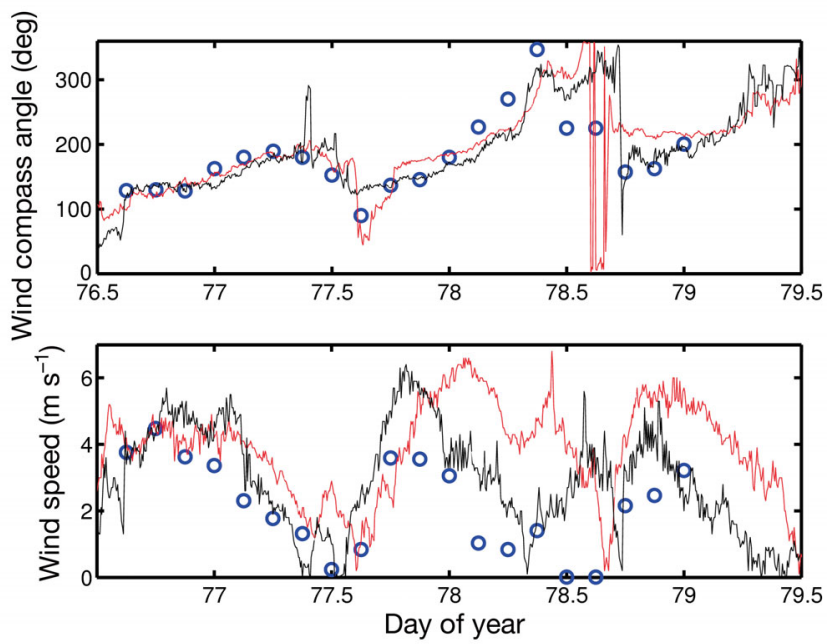

Fig. 7. Comparison of America SEAS (AMSEAS) 3 h Navy regional Coupled Ocean/Atmosphere Mesoscale Prediction System (COAMPS) wind estimates (O) to Coastal-Marine Automated Network (C-MAN) 10 min wind averages. (Black: Saint Louis Bay Station WYCM6, 30.326 ${ }^{\circ}$, $89.326^{\circ} \mathrm{W}$; red: Ship Island Station GPOM6, $30.230^{\circ} \mathrm{N}, 88.982^{\circ} \mathrm{W}$ ). Days 76 to 79 of the year correspond to calendar dates 17 to 20 March 2011

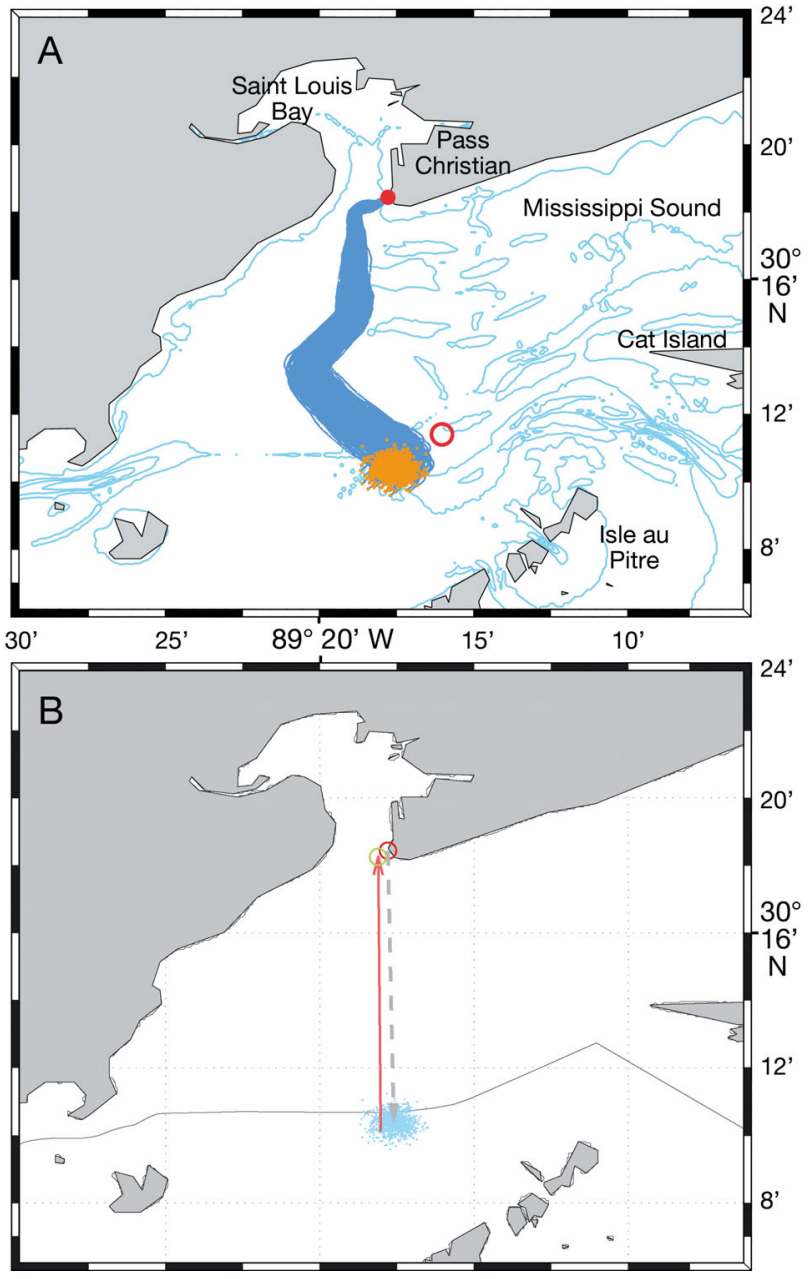


Monthly summaries of outbound and inbound tracks showed strong agreement between the 2 trajectories, suggesting the estimated backtracks were good approximations (Fig. 9). The greatest discrepancies occurred for backtracks and forward tracks that included island interactions where the impingement on a shoreline confused the backtrack. In Fig. 9B, 2 backtracks from the south side of Horn Island gave an outbound vector southwest toward the Chandeleur Islands. However, the inbound vectors stopped short before reaching Horn Island, demonstrating that, in this case, the original mortality likely occurred somewhere between the 2 estimates. Overall, for most comparisons, the 2 vectors agreed.
The final graphical summary of the backtrack analysis suggests that the majority of strandings of sea turtles that occurred on the Mississippi beaches during the spring/summer 2011 study period likely originated from sites just offshore, in a region encompassing the western Mississippi barrier islands and northeastern Louisiana State waters (Fig. 10). Probability contours show about an $8 \times$ higher likelihood for a region including Ship and Cat Islands and the northeastern Louisiana waters (near Isle au Pitre). Some backtracks suggest sources in the northern Chandeleur Sound as well. The probability maps also demonstrate a very low likelihood that mortalities originated in offshore oceanic waters. The PDF of sea turtle mortality for waters outside the barrier islands rapidly drops from

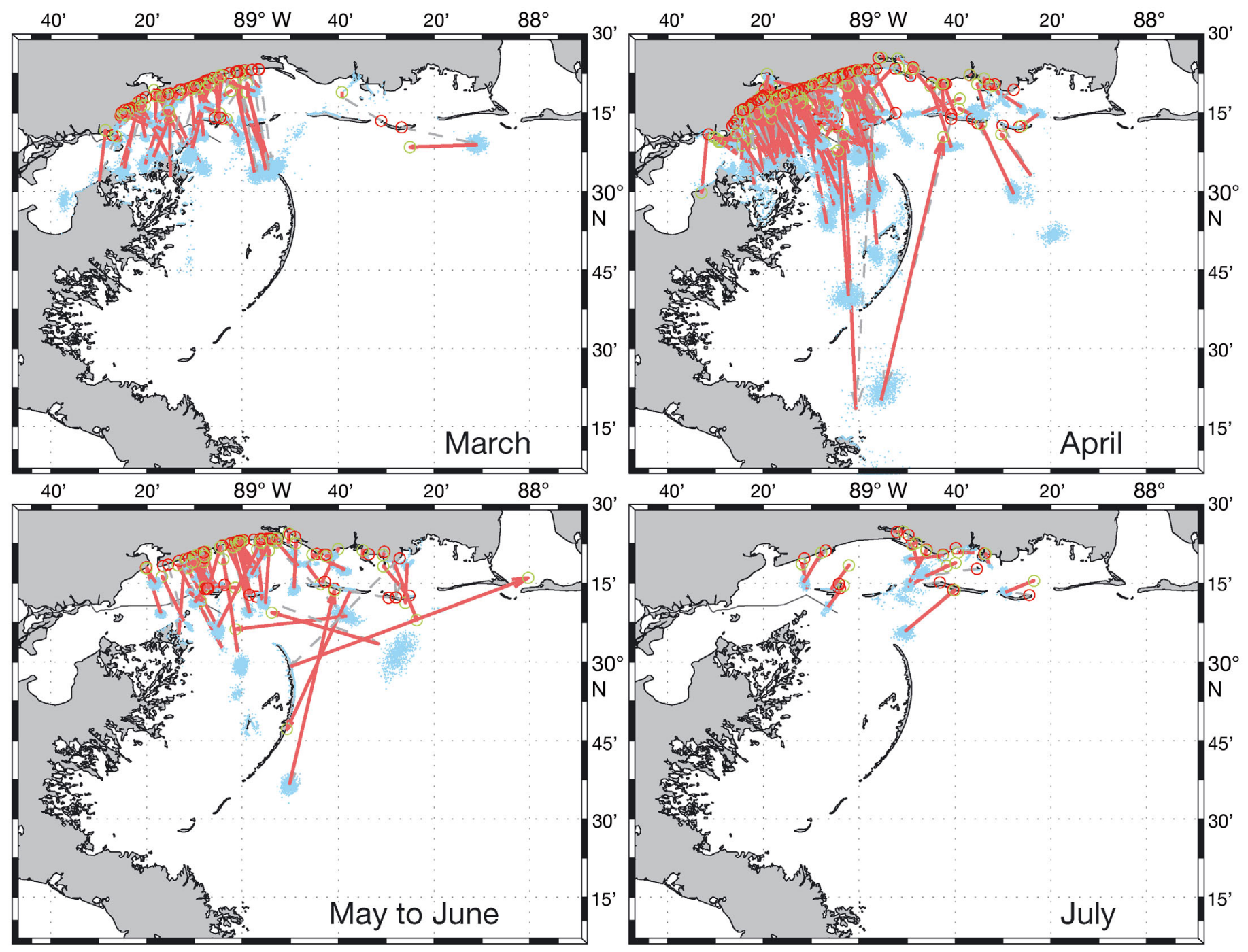

Fig. 9. All strandings from coastal Mississippi subdivided into months with backtrack and forward track trajectories shown as vector lines connecting average particle endpoint positions, (---) outbound backtrack trajectory with cloud (blue) of estimated source location, $(-)$ inbound forward trajectory. (O) Original stranding locations; $(\bigcirc)$ forward trajectory estimates of standing location. $(A)$ March, $(B)$ April, (C) May to June, (D) July 


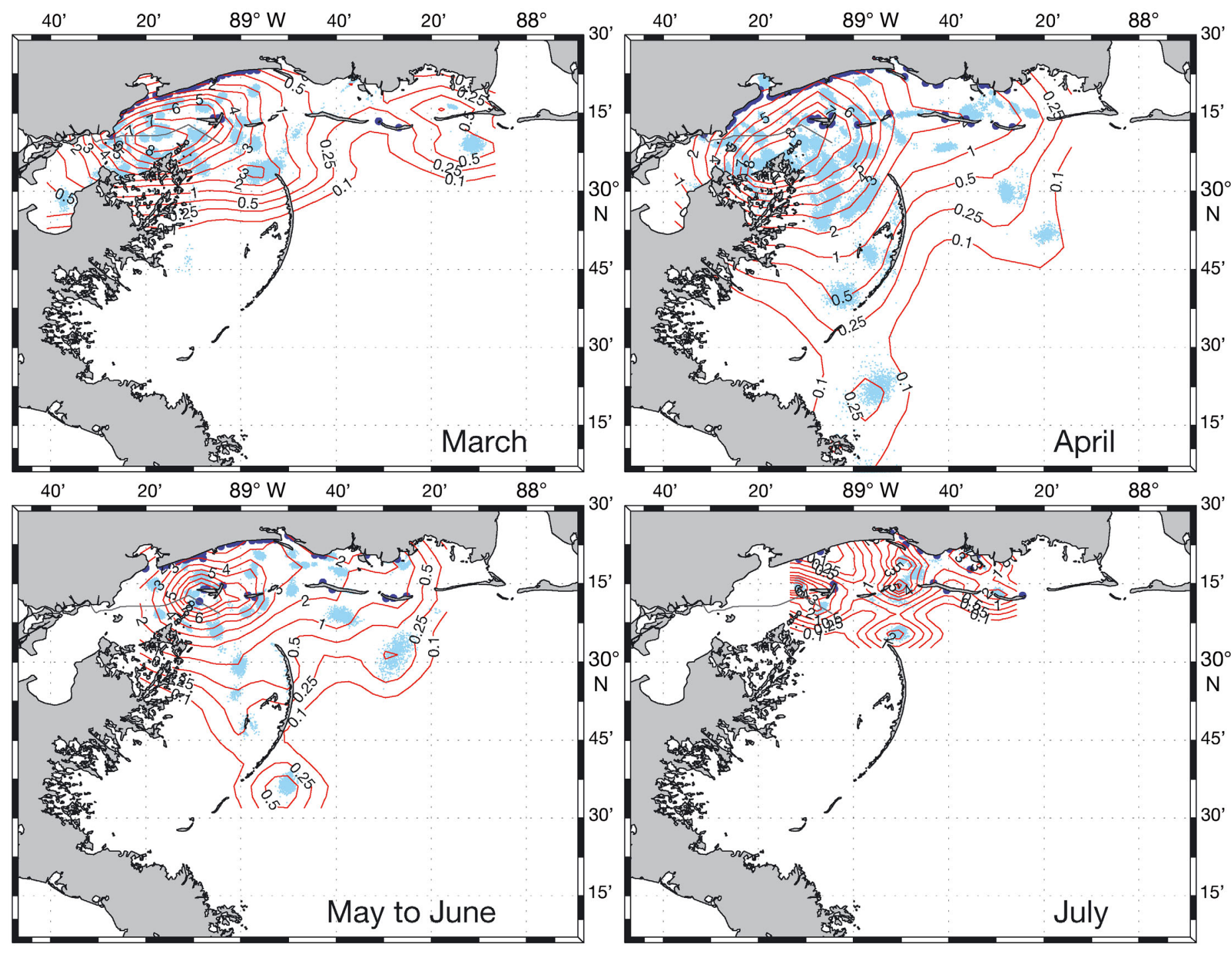

Fig 10. Backtrack Probability Density Function (PDF) of turtle mortality for sea turtle carcasses found at stranding locations (•). The PDF of mortality gives a factor of ' 1 ' if all turtles are spread out evenly, and higher values for locations with increased 'likelihood', so a value of 8 indicates an 8 times higher density of particles (turtles) originating from that area. Clouds of individual particles ( $\mathrm{n}=1000$ per stranding) are shown in light blue. (A) March, (B) April, (C) May to June, (D) July

1 (equal chance) to below 0.1 (1/10th as likely). Highest densities and greatest probabilities of mortality occurred for the April strandings (Fig. 10B).

\section{DISCUSSION}

The backtracking model described here was the first model used to predict sea turtle mortality locations in the northern GOM. Quantitative data on the origin of stranded sea turtles are generally lacking, in part because of the safeguards needed for conducting experiments on endangered species. Additionally, the warm and turbulent water in near-shore environments accelerates decomposition and reduces the number of dead turtles that are discovered. The presumed time of death, duration of submergence, floating and drift of LK41, along with the AMSEAS model-estimated bottom currents, temperatures, and surface winds and currents, provided good corroboration of previous temperature-dependent rates of sea turtle decomposition and floating (B. Higgins et al. unpubl.), and are currently the best estimate of sea turtle carcass leeway. Our observations matched the very limited information available. In a carcass release study in Core Sound, North Carolina, the only observation given is that most carcasses were noted to float and to travel in the direc- 
tion of the prevailing winds (North Carolina Wildlife Resources Commission, 1507 Ann St., Beaufort, NC, 2007 unpubl.), which suggests suggests that in general the wind force dominates over the tidal currents in this type of shallow estuary.

The estimate of carcass leeway of $3.5 \%$ of wind speed presented here is a single indirect estimate using a mesoscale ocean model and drift measured using Argos positional information. This estimate fits well within the overall range for other drifting objects. For example, a variety of objects reviewed in Breivik et al. (2011) included persons in a survival suit $(2 \%)$; life rafts (3 to $6.8 \%)$; fishing vessels $(2.7$ to $4.2 \%$ ); and sport boats (6 to $7 \%$ ).

Although the majority of dead sea turtles were found on Mississippi beaches, backtrack analysis of the strandings indicate that much of the at-sea mortality probably occurred in a region just southwest of Cat Island and included inshore Louisiana state waters to the northern part of Chandeleur Sound (Fig. 1). Searching for a cause for the strandings should include consideration of all natural events and anthropogenic activities in this region, which includes inshore waters of both Mississippi and Louisiana. An increase in reporting and monitoring may also have contributed to higher stranding numbers. Prior to the 2010 DWH oil spill, outreach and education about sea turtle strandings was minimal and many strandings may have gone unreported (DEIS 2012). The oil spill created enormous media coverage and research in the region, resulting in increased beach monitoring for wildlife and outreach on who to call if injured wildlife is observed. Recent studies of site fidelity (Lyn et al. 2012) demonstrate the importance of the nearshore coastal region of north Chandeleur Sound and the Mississippi barrier islands in April as habitat for juvenile Kemp's ridley sea turtles. Clearly, further studies of their behavior, abundance, and habitat use in this region are of interest.

The timing of strandings originating from this region in April and why strandings do not occur at other times may in part be explained by the water temperatures in the region. Juvenile Kemp's ridley turtles in the GOM show a preference for water temperatures above $18^{\circ} \mathrm{C}$ (Schmid \& Witzell 2006) and likely move into the shallow water as temperatures rise above $18^{\circ} \mathrm{C}$. The Louisiana and Mississippi coastal waters usually reach $20^{\circ} \mathrm{C}$ in early April, at which time juvenile Kemp's ridley turtles are probably moving into this region. If these turtles experience mortality, regardless of the cause, the carcasses are likely to drift for about $5 \mathrm{~d}$, impinging into Mississippi Sound and beaches, as demonstrated in this study. Later in May and into June, water temperatures warm, and carcasses are much more likely to decompose and not make the transit to the beaches.

Using beach strandings as an indicator of at-sea sea turtle mortality may be biased by any combination of seasonal changes in winds, currents and temperature. Epperly et al. (1996) suggested that beach strandings during winter along the beaches of North Carolina are a poor indicator of at-sea mortalities because of the seasonal variability of offshore ocean currents. In the Mississippi Sound, currents are relatively weak in comparison $\left(0.1\right.$ to $0.2 \mathrm{~m} \mathrm{~s}^{-1}$ depending on the tide) to the currents off North Carolina (0.2 to $1.0 \mathrm{~m} \mathrm{~s}^{-1}$ )(AMSEAS and NCOM US East archives, www.northerngulfinstitute.org/edac/). Additionally, the seasonally driven onshore southeasterly winds begin in April and continue through August (Johnson 2008). However, surface water temperatures rise rapidly from 9 to $30^{\circ} \mathrm{C}$ from January through June. Thus, although seasonal wind pattern changes likely play some role in Mississippi, changes in ocean temperature probably have a larger role in Mississippi Sound than in North Carolina. The very warm water temperatures near $30^{\circ} \mathrm{C}$ occur in the northern Gulf in late May and persist through the summer months. These warm water temperatures likely play a bigger role in biasing the effectiveness of beach strandings as an indicator of at-sea mortalities. The change in timing for carcasses to pass from freshly dead (Code 1) to just skeletal remains (Code 5) is very likely to influence whether mortalities are detected on local beaches. Water temperatures within the AMSEAS data along the tracks indicated 10 to $15^{\circ} \mathrm{C}$ in January through February, 16 to $23^{\circ} \mathrm{C}$ in March, 21 to $26^{\circ} \mathrm{C}$ in April, 22 to $28^{\circ} \mathrm{C}$ in May, 27 to $31^{\circ} \mathrm{C}$ in June, 27 to $31^{\circ} \mathrm{C}$ in July and peaked at 28 to $33^{\circ} \mathrm{C}$ in August. These estimates suggest submergence times of 4 to $5 \mathrm{~d}$ and drift times of $5 \mathrm{~d}$ early in the spring at $20^{\circ} \mathrm{C}$, becoming shorter at $30^{\circ} \mathrm{C}$, with submergence times of approximately $24 \mathrm{~h}$ and drift times of about $48 \mathrm{~h}$, based on the study by B. Higgins et al. (unpubl.) and our analysis. Thus by May and into June, higher water temperatures are such that drifting carcasses will only float for about $2 \mathrm{~d}$ and are less likely to drift to the popular sand beaches of Mississippi.

The backtracking model presented here can be an essential tool for managers, state agencies and law enforcement during sea turtle stranding events in the northern GOM. Combined with strandings data and necropsy results, it provides potential focus areas for investigation of mortality factors (e.g. bycatch in fisheries, biotoxins). It also provides potential focus areas for law enforcement activities to ensure that required 
sea turtle bycatch reduction measures are in use. Future research including the use of sea turtle effigies and drifters should be conducted to improve model accuracy. Hopefully, with higher resolution ocean models and studies with model drifters, the leeway estimate can be refined to provide a better backtrack capability for determining the sources of sea turtle mortalities. The model could also be modified or developed to backtrack mortality locations of other species of sea turtles or small marine mammals.

Acknowledgements. The authors thank all of the individuals and members of the National Sea Turtle Stranding and Salvage Network that responded to the sea turtle strandings. We also thank W. Teas for her assistance with collating the stranding data, and numerous colleagues, including D.-S. Ko, F. L. Bub, J. M. Harding, and A. R. Parsons, whose advice and encouragement led to the implementation of the model. S. Epperly, C. Gledhill, L. Desfosse, and 2 anonymous reviewers kindly provided reviews and suggestions to improve the manuscript. This research was supported by general operating funds within the NMFS, IMMS, and Florida Fish Wildlife Conservation Commission.

\section{LITERATURE CITED}

Breivik Ø, Allen A, Maisondieu C, Roth JC (2011) Windinduced drift of objects at sea: The leeway field method. Appl Ocean Res 33:100-109

Breivik Ø, Bekkvik TC, Wettre C, Ommundsen A (2012) BAKTRAK: backtracking drifting objects using an iterative algorithm with a forward trajectory model. Ocean Dyn 62:239-252

Carlson DF, Fredj E, Gildor H, Rom-Kedar V (2010) Deducing an upper bound to the horizontal eddy diffusivity using a stochastic Lagrangian model. Environ Fluid Mech 10:499-520

Carniel S, Umglesser G, Sclavo M, Kantha LH, Monti S (2002) Tracking the drift of a human body in the coastal ocean using numerical prediction models of the oceanic, atmospheric and wave conditions. Sci Justice 42:143-151

Carr AF (1977) Crisis for the Atlantic ridley. Mar Turtle Newsl 4:2-3

Chen S, Cummings J, Doyle J, Hodur RH and others (2003) COAMPS Version 3.0. Model description: general theory and equations. NRL Tech Note NRL/PUB/7500-0-3-448, Naval Research Laboratory, Monterey, CA

Crowder L, Heppell S (2011) The decline and rise of a sea turtle: how Kemp's ridleys are recovering in the Gulf of Mexico. Solutions 2:67-73

DEIS (Draft Environmental Impact Statement) (2012) Draft environmental impact statement to reduce incidental bycatch and mortality of sea turtles in the southeastern U.S. shrimp fisheries. NOAA, NMFS, St. Petersburg, FL. sero.nmfs.noaa.gov/pr/ShrimpFishery_SeaTurtle.htm (accessed 20 June 2012)

Epperly SP, Braun J, Chester AJ, Cross FA, Merriner JV, Tester PA, Churchill JH (1996) Beach strandings as an indicator of at-sea mortality of sea turtles. Bull Mar Sci 59:289-297
Frazier JG, Arauz R, Chevalier J, Formia A and others (2007) Human-turtle interactions at sea. In: Plotkin PT (ed) Biology and conservation of ridley sea turtles. Johns Hopkins University Press, Baltimore, MD, p 253-294

$>$ Hart KM, Mooreside P, Crowder LB (2006) Interpreting the spatio-temporal patterns of sea turtle strandings: going with the flow. Biol Conserv 129:283-290

Heppell SS, Burchfield PM, Pena LJ (2007) Kemp's ridley recovery. How far have we come, and where are we headed? In: Plotkin PT (ed) Biology and conservation of ridley sea turtles. Johns Hopkins University Press, Baltimore, MD, p 325-335

Higgins B, Cannon A, Gitschlag G (2007) Sea turtle decomposition study. Unpubl. report, National Marine Fisheries Service, Southeast Fisheries Science Center, Galveston, TX

> Hodur RM (1997) The Naval Research Laboratory's Coupled Ocean/Atmosphere Mesoscale Prediction System (COAMPS). Mon Weather Rev 125:1414-1430

Johnson DR (2008) Ocean surface current climatology in the northern Gulf of Mexico. Gulf Coast Research Laboratory Report, Ocean Springs, MS. www.usm.edu/gcrl/user_ files/Donald.Johnson.NGOM.currents.pdf (accessed 15 August 2012)

Johnson DR, Perry HM, Lyczkowski-Shultz J (2013) Connections between Campeche Bank and red snapper populations in the Gulf of Mexico via modeled larval transport. Trans Am Fish Soc 142:50-58

Lyn H, Coleman A, Broadway M, Klaus J, Finerty S, Shannon D, Solangi M (2012) Displacement and site fidelity of rehabilitated immature Kemp's ridley sea turtles (Lepidochelys kempii). Mar Turtle Newsl 135: $10-13$

Magnuson JJ, Bjorndal KA, DuPaul WD, Graham GL and others (1990) Decline of the sea turtles: causes and prevention. National Research Council, National Academy Press, Washington, DC

> Marinone SJ, Gutiérrez OQ, Parés-Sierra A (2004) Numerical simulation of larval shrimp dispersion in the northern region of the gulf of California. Estuar Coast Shelf Sci 60: 611-617

> Megyesi MS, Nawrocki SP, Haskell NH (2005) Using accumulated degree-days to estimate the postmortem interval from decomposed human remains. J Forensic Sci 50: 618-626

MTSG (Marine Turtle Specialist Group) (1996) Lepidochelys kempii. In: IUCN 2013. IUCN Red List of Threatened Species. Version 2013.1. www.iucnredlist.org (accessed 20 June 2012)

NMFS (National Marine Fisheries Service), US Fish and Wildlife Service, and SEMARNAT (2011) Bi-national recovery plan for the Kemp's ridley sea turtle (Lepidochelys kempii), 2nd revsn. National Marine Fisheries Service, Silver Spring, MD

NOAA (National Oceanic and Atmospheric Administration) (2011) Agencies partner to help save endangered Kemp's ridley sea turtles, NOAA News. www.noaanews.noaa. gov/stories2011/20110922_kempsridley.html (accessed 20 June 2012)

North EW, Gallego A, Petitgas P (eds) (2009) Manual of recommended practices for modelling physical-biological interactions during fish early life. ICES Cooperative Research Report No. 295. ICES, Copenhagen

Paris CB, Cowen RK, Claro R, Lindeman KC (2005) Larval transport pathways from Cuban snapper (Lutjanidae) 
spawning aggregations based on biophysical modeling. Mar Ecol Prog Ser 296:93-106

Peltier H, Dabin W, Daniel P, Van Canneyt O, Doremus G, Huon M, Ridoux V (2012) The significance of stranding data as indicators of cetacean populations at sea: modelling the drift of cetacean carcasses. Ecol Indic 18:278-290

Rogers WE, Hwang PA, Wang DW (2003) Investigation of wave growth and decay in the SWAN model: three regional-scale applications. J Phys Oceanogr 33:366-389

Schmid JR, Witzell WN (2006) Seasonal migrations of immature Kemp's ridley turtles (Lepidochelys kempii Garman) along the west coast of Florida. Gulf Mex Sci 24:28-40

Seim HE, Kjerfve B, Sneed JE (1987) Tides of Mississippi Sound and the adjacent continental shelf. Estuar Coast Shelf Sci 25:143-156

Editorial responsibility: Matthew Godfrey,

Beaufort, North Carolina, USA
Seney EE, Landry AM Jr (2011) Movement patterns of immature and adult female Kemp's ridley sea turtles in the northwestern Gulf of Mexico. Mar Ecol Prog Ser 440: 241-254

Shaver DJ, Rubio C (2008) Post-nesting movement of wild and head-started Kemp's ridley sea turtles Lepidochelys kempii in the Gulf of Mexico. Endang Species Res 4: 43-55

Trenberth KE, Large WG, Olson JG (1990) The mean annual cycle in global ocean wind stress. J Phys Oceanogr 20: 1742-1760

> Vincent C, McConnell BJ, Ridoux V, Fedak MA (2002) Assessment of Argos location accuracy from satellite tags deployed on captive gray seals. Mar Mamm Sci 18: 156-166

Submitted: September 10, 2012; Accepted: May 14, 2013 Proofs received from author(s): August 14, 2013 